\title{
Does Microcredit Reach the Poor and Vulnerable? Evidence from Northern Bangladesh
}

\author{
Sajeda Amin, Ashok S. Rai and Giorgio Topa \\ CID Working Paper No. 28 \\ December 2001
}
(C) Copyright 2001 Sajeda Amin, Ashok S. Rai, Giorgio Topa and the President and Fellows of Harvard College

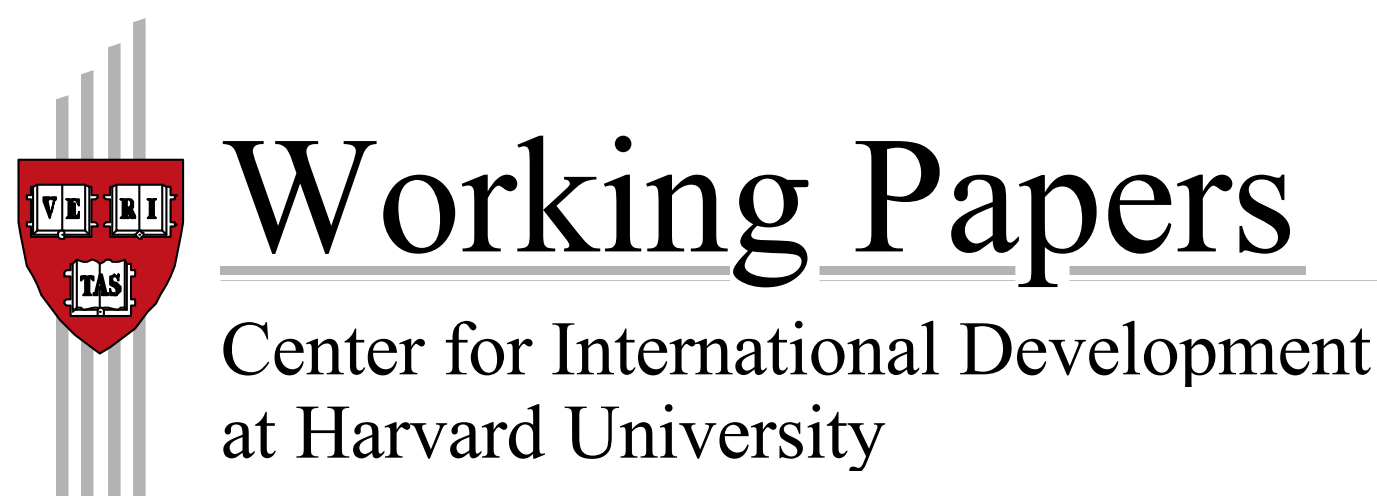




\title{
Does Microcredit Reach the Poor and Vulnerable? Evidence From Northern Bangladesh
}

\author{
Sajeda Amin* Ashok S. Rai ${ }^{\dagger} \quad$ Giorgio Topa ${ }^{\ddagger \S}$
}

December 2001

We thank Chris Hartwell, Anna Musatti and especially Dilip Parajuli for excellent research assistance. Suggestions from two anonymous referees, Abhijit Banerjee, Marcel Fafchamps, Chris Flinn, Wilbert van der Klaauw, Anna Paulson, Robert Townsend, Frank Vella and seminar participants at Boston University, Brown, Harvard, M.I.T., Penn State, Population Council, and Yale are much appreciated. Giorgio Topa gratefully acknowledges financial support from the C.V. Starr Center at NYU. All errors are our own.

*Population Council, One Dag Hammarskjold Plaza, New York NY 10017

${ }^{\dagger}$ Center for International Development, Harvard University, 79 JFK St., Cambridge MA 02138.

†Department of Economics, New York University, 269 Mercer St., New York, NY 10003.

§Emails: samin@popcouncil.org, ashok_rai@harvard.edu and giorgio.topa@nyu.edu 


\begin{abstract}
This paper evaluates whether microcredit programs such as the popular Grameen Bank reach the relatively poor and vulnerable in two Bangladeshi villages. It uses a unique panel dataset with monthly consumption and income data for 229 households before they received loans. We find that while microcredit is successful at reaching the poor, it is less successful at reaching the vulnerable. Our results also suggest that microcredit is unsuccessful at reaching the group most prone to destitution, the vulnerable poor. Our main contribution is to explicitly evaluate the targeting of an anti-poverty intervention using the efficient risk-sharing framework in Townsend (1994).

JEL Codes: O16, I38, Q12

Keywords: Poverty, Vulnerability, Microcredit, Targeting, Risk Sharing, Grameen Bank.
\end{abstract}




\section{Introduction}

Subsidized credit has a disappointing history of being politically manipulated and diverted from its intended beneficiaries, the poor. Instead the rich have benefited disproportionately from such programs. For instance, 80 percent of the $\$ 56$ million subsidies provided to Costa Rica's largest bank in 1974 went to large wealthy farmers (Vogel, 1984). The non-poor were just as likely as the poor to participate in a Indian government subsidized credit scheme in the 1980s (Ravallion and Datt, 1995). Yet in recent years, subsidized lending programs such as the Grameen Bank have become "the world's hot idea to reduce poverty (New York Times, 1997)." These "microcredit" schemes provide small loans without collateral to households excluded by the formal financial sector in many developing countries (Morduch, 1999). While there have been numerous attempts to assess the impact of these programs on a variety of outcomes (Pitt and Khandker, 1998a, Morduch, 1998, and others), there has been little research on how well targeted modern microcredit programs actually are. ${ }^{1}$

This paper uses a unique data set from two villages in Northern Bangladesh to test if members of microcredit programs are poorer and more vulnerable than non-members. A household is defined as poor if it has low consumption levels, and vulnerable if it is unable to smooth consumption in the face of idiosyncratic income fluctuations. We use consumption and income data for 229 households for twelve months in 1991 - 92 to identify households that are poor and vulnerable. We then check to see which of these households joined a microcredit program by 1995. Since microcredit organizations only just began to give loans in the two villages in $1991-92$, we can ignore issues of endogeneity for the most part. The three programs in our study, Grameen Bank, Bangladesh Rural Advancement Committee (BRAC) and Association for Social Advancement (ASA) are the largest microcredit providers in Bangladesh, and among the largest in the world.

We find that modern microcredit programs are definitely more successful at reaching the poor than their predecessors. The probability that a microcredit member is below the poverty line is substantially higher than that of a randomly picked household in both villages. A 24 percent decrease in monthly consumption at the mean increases the probability of joining a

\footnotetext{
${ }^{1}$ Navajas et al (1998) and Pitt and Khandker (1998b) are exceptions. Unlike this paper, they use data on households after they have joined microcredit programs.
} 
microcredit program by about 6 to 7 percent. In contrast, microcredit is less successful at reaching the vulnerable. We find that the vulnerable are more likely to join microcredit programs only in the richer of the two villages. Most crucially, we find no evidence that microcredit reaches the households most in need of assistance, the vulnerable poor. Indeed, our results suggest that the vulnerable poor are excluded from microcredit in the poorer village.

Many rural households lack insurance against risks of sickness, floods, crop damage and fluctuations in prices. Of these, household-specific risks but not aggregate shocks can be insured against at the village level. We think of households that are unable to perfectly insure themselves in the event of household-specific shocks as vulnerable. The recent World Development Report uses a similar definition: "vulnerability measures...the likelihood that the shock will result in a decline in well-being (World Bank, 2001, p.139)."

In principle, both rich and poor households could be labeled as vulnerable according to our measure. ${ }^{2}$ Our data show that poorer households are more vulnerable than the rich, however. Reaching the vulnerable poor is considered to be crucial to any poverty reduction strategy (World Bank, 2001). Further, protecting the vulnerable poor is an explicit goal of microcredit practitioners and a means to promote repayment. ${ }^{3}$ Grameen explicitly bundles insurance with credit provision: borrowers have access to repeat loans from a disaster fund and a group savings fund when they are hit with an adverse shock. Impact studies emphasize microcredit's role in smoothing consumption (Morduch, 1998, and Pitt and Khandker, 1998a).

The main contribution of this paper is to explicitly evaluate the targeting of an anti-poverty intervention using the general equilibrium framework of risk sharing in village economies (Townsend, 1994). Since the presence of vulnerable households indicates a market or institutional failure, it can

\footnotetext{
${ }^{2}$ There is an issue of semantics here. The inability to perfectly insure against idiosyncratic risk has different welfare implications for a poor than for a rich household, since the former is more likely to fall into destitution following an adverse income shock. Therefore, some readers would no doubt have preferred that we use the term "vulnerable" only for uninsured poor households and not for uninsured rich households. Since we separately analyze whether microcredit reaches the poor, the uninsured, and the uninsured poor, we do (indirectly) address their concern.

${ }^{3}$ According to Grameen Bank's deputy managing director: "In view of the vulnerabilities of its targeted clientele, Grameen has carefully built into its credit delivery system innovative safety features. These act like shock absorbers, enabling Grameen members to better cope with natural as well as man-made disasters. Without them the credit delivery system would not have functioned at all... (Shams, 1992, p. 13, emphasis added)."
} 
be welfare improving to assist the vulnerable, particularly the vulnerable poor. We compute several alternative vulnerability measures to control for measurement error and to allow for different specifications of the basic risk sharing model. Our results on the relationship between vulnerability and microcredit membership are robust to these alternatives. We also compare our vulnerability measure to more commonly used measures of consumption variability, and argue that such measures are inadequate proxies for vulnerability. In contrast to our vulnerability measure, we find that rich households have more variable consumption than the poor.

The rest of the paper is organized as follows. Section 2 describes the two villages and the data. Section 3 derives a measure of vulnerability and describes its estimation. Section 4 reports our findings on whether microcredit reaches the poor and vulnerable. Section 5 concludes.

\section{Data}

The study uses transactions data collected over 12 months in two villages (called $A$ and $B$ to preserve anonymity) in the district of Rajshahi in northwest Bangladesh. Table 1 reports the distribution of occupations within each village. Village $A$ is primarily agricultural while village $B$ is more diversified in its income sources: only 20 percent of the households in village $A$ but over half the households in village $B$ do not report agriculture or daily labor as their main occupation. Village $B$ has several small shops, a marketplace (haat) that meets twice a week and attracts 200 vendors, and local government offices. All major marketing activities for village $A$ are held in marketplaces outside the village. Both villages grow three rice crops a year. In addition, village $A$ grows betel leaf, a cash crop, and village $B$ has several jointly owned mango orchards (Amin, 1998).

In 1991, there were 395 and 398 households respectively in the two villages. Of these, 120 households were sampled in each village. Male headed households had a $\frac{1}{4}$ chance of being surveyed, while all female headed households were sampled. The lack of complete data for a few households brought the number of units in our sample down to 112 for village $A$ and 117 for village $B$. Households were followed for 12 rounds and data on income, expenditure, asset transactions, time use, loans and gifts were collected at each round. ${ }^{4}$ Each round corresponds roughly to a calendar month, with rounds

\footnotetext{
${ }^{4}$ Resident research teams of 2 male and 2 female interviewers who were recent university
} 
starting in September 1991 for village $A$ and October 1991 for village $B$.

Two consumption measures were created for each of the sampled households over the 12 months: food consumption and all (non-durable) consumption. Food consumption includes consumption from own production of wheat and rice, purchased wheat and rice, other food purchases (e.g. vegetables and pulses), other food consumption from own produce, net meals received as wages or gifts. All consumption adds expenditure on services and other non-durable purchases (e.g. tobacco and medicines). Measures of household income and revenue were also created. ${ }^{5}$ All income includes net profits from own crop production, net wages earned, net profits from trading, self employment and business activities, and rent. Revenue comprises gross profits and wages earned. Neither the all income measure nor the revenue measure include net borrowing and saving or net gifts received. Each of these are assumed to be smoothing devices used to augment consumption when incomes are low or to put aside resources when incomes are high. Field observation and the detailed transactions data indicate that zero nominal interest loans were common within both villages, and gift exchange in the form of meals or food was widespread. Table 2 reports summary statistics for the two villages. The unit of observation is a household. Village $B$ is wealthier than village $A$ : adult equivalent monthly consumption, income, and revenues are all higher in $B$. The mean adult equivalent monthly income is 429 taka (approximately $\$ 11$ ) in village $A$ and 537 taka in village $B$ (approximately $\$ 14$ using the 1992 exchange rate of $\$ 1=38$ taka). The daily agricultural wage in both villages in 1991 - 92 was 20 taka plus two meals, valued at about 7 taka each. So a day's agricultural work was worth less than $\$ 1$. Since the coefficient of variation of consumption is lower than that of income or revenues for both villages, there appears to be some risk sharing by households. There is considerable idiosyncratic (and hence diversifiable) risk in this economy: incomes and revenue do not comove across households.

graduates lived in each village between June 1991 and November 1992. The principal investigator spent approximately one week every month in the villages to supervise and participate in data collection.

${ }^{5}$ Consumption, income and revenue are in per adult equivalent terms throughout the paper. The following age-sex weights were used: 1.0 for adult males, 0.9 for adult females, 0.94 for males aged $13-18,0.83$ for females aged $13-18,0.67$ for children aged $7-12,0.52$ for children aged $4-6,0.32$ for toddlers aged $1-3$, and 0.05 for infants. These weights are the same as those used by Townsend (1994) which are based on a south Indian dietary survey. 
Wodon (1997) calculates a poverty line of 425 taka monthly per capita consumption for Rajshahi for 1991-92 using the cost of basic needs method. ${ }^{6}$ According to his estimates, 62 percent of rural Rajshahi and 47 percent of rural Bangladesh is below the poverty line. Village $A$ is slightly poorer than the average Rajshahi village: 68 percent of the sampled households are below the poverty line. On the other hand, village $B$ is slightly richer than the average Rajshahi village but still poor relative to the national average: 54 percent of its sampled households are below the poverty line. ${ }^{7}$

A resurvey of both these villages was carried out in 1995. In particular, we have information on the number of households (or their splits) that had joined Grameen, BRAC and ASA by $1995 .^{8}$ This is the unique feature of the data that we exploit in our analysis. In $1991-92$, when the first survey was conducted, Grameen Bank had only begun to establish their presence in the two villages. In village $A, 5$ sampled households took their first loans from Grameen before the end of the survey in 1992, of which 2 took loans in the last two months of the survey. In village $B, 14$ sampled households took Grameen loans before the end of the survey in 1992, of which 4 households took loans in the last quarter of the survey. ${ }^{9}$ By 1995, Grameen, BRAC and ASA had firmly established their loan program in these villages. Throughout this paper, consumption and income data (and therefore our measures of vulnerability) are based on the 1991 - 92 data. Microcredit membership data, on the other hand, are derived from the 1995 resurvey. A household's average consumption level and vulnerability may of course change between 1991 - 92 and the year just before it joined a microcredit program, but we have no data for the intervening period to control for this possibility. However, once a microcredit program begins lending in an area it expands quickly and other microcredit programs follow soon after. So it is likely that households that joined microcredit programs did so soon after the 1991-92

\footnotetext{
${ }^{6}$ The poverty line was set by computing the (district specific) cost of a food basket that enabled households to meet the normative nutritional requirement of 2.5 kilocalories, and adding to this an estimated allowance for non-food consumption.

${ }^{7}$ The percentages of households below the poverty line have been weighted to reflect the oversampling of female-headed households.

${ }^{8}$ Households that split between 1992 and 1995 were treated as a single unit. Field observations suggest that split households maintain very close social and economic ties, and appear to act as a single large unit.

${ }^{9}$ For those households that had already joined Grameen before the end of the survey our estimates of poverty and vulnerability levels may be biased by the loans taken from Grameen. We discuss the likely direction of such bias, wherever applicable, in Section 4.
} 
data was collected.

Table 3 summarizes the village composition in terms of several household categories (landlessness, female headship, education level of the household head). ${ }^{10}$ In addition, the number of households with at least one microcredit member by 1995 is reported. About one third of all sampled households in each village had joined a microcredit program by this time. Grameen membership had risen to 10 sampled households in village $A$ and 17 sampled households in village $B$, and total microcredit membership was 38 sampled households in each village.

Microcredit loan use is typically quite fungible. So even though the loans are sometimes given for production, they can be diverted for consumption smoothing. Todd (1996) describes how paddy husking and the purchase of cows are commonly reported uses of Grameen loans, but in practice loans are often used to lease land and repay other loans (a consumption smoothing activity).

\section{Measuring vulnerability}

Under commonly made assumptions (separability of consumption and leisure, common rates of time preference, additively separable preferences over time) efficient risk sharing within a village implies that household consumption should move only with aggregate consumption and not with household income (Deaton, 1997, pages $372-383$, and Townsend, 1994). We measure vulnerability based on this risk sharing test. Instead of looking at specific smoothing mechanisms (such as loans, gifts, savings or asset sales), vulnerability is derived from household outcomes (consumption and income). In this Section we describe how we estimate a baseline vulnerability measure for each household and propose alternative vulnerability measures to study its robustness. We also report on the correlation of vulnerability with poverty and with measures of the variability of consumption.

\footnotetext{
${ }^{10}$ In regressions of household average monthly (all) consumption on household characteristics, we found that female headed and larger households, and households with less arable land and more elderly members had lower consumption in both villages.
} 


\subsection{Risk Sharing}

A key feature of efficient risk sharing within the village is that changes in log marginal utility of consumption must be equated across households at each date and state. Suppose households have a constant absolute risk aversion (CARA) utility function:

$$
u^{h}\left(c_{t}^{h}\right)=-\frac{1}{\zeta_{t}^{h}} n_{t}^{h}\left[\exp \left(-\sigma \frac{c_{t}^{h}}{n_{t}^{h}}\right)\right]
$$

where $c_{t}^{h}$ denotes consumption for household $h$ at time $t, n_{t}^{h}$ is the (age-sex adjusted) number of male adult equivalents in the household at time $t, \zeta_{t}^{h}$ is a preference shock and $\sigma$ is the coefficient of absolute risk aversion. Efficient risk sharing then implies the following for each household $h$ :

$$
\Delta\left(\frac{c_{t}^{h}}{n_{t}^{h}}\right)=-\frac{1}{\sigma} \kappa_{t}-\frac{1}{\sigma} \Delta \ln \zeta_{t}^{h}
$$

where $\Delta x_{t} \equiv x_{t}-x_{t-1}$ for any variable $x_{t}$, and $\kappa_{t}$ is the first difference in logarithms of the appropriately discounted multiplier associated with the aggregate resource constraint. So consumption across agents should comove (modulo variations due to preference shocks), and changes in a household's consumption should not be affected by changes in that household's income.

Equation (1) constitutes the basis of our estimation strategy. If full risksharing is in place and preference shocks can be treated as mean zero error terms that are uncorrelated with changes in income and with time dummies, then changes in per-adult-equivalent consumption over time should comove across households. Household consumption should only be affected by aggregate fluctuations in the village, and not by idiosyncratic shocks to the household's own income or resources. Our estimation strategy focuses on identifying individual households within each village that are vulnerable to idiosyncratic risk.

So far we have implicitly assumed that the household utility stays the same if one doubles both the total consumption in the household and the number of adult equivalents. But a bigger household may be more efficient. First differencing consumption will eliminate economies of scale that are fixed through time, however. Only 3 households in village $A$ and 2 in village $B$ change composition during the 12 months of the sample, so we can safely ignore household economies of scale. 


\subsection{Estimation}

We estimate a linear regression model based on equation (1) to identify vulnerable households. If we treat the $\zeta_{t}^{h}$ preference shocks as mean zero error terms that are uncorrelated with the other regressors, equation (1) suggests the following regression equation:

$$
\Delta \widetilde{c}_{t}^{h}=\alpha^{h} \Delta \widetilde{y}_{t}^{h}+\phi_{t} \cdot M D_{t}+\varepsilon_{t}^{h} .
$$

where $\widetilde{c}_{t}^{h} \equiv c_{t}^{h} / n_{t}^{h}$ denotes per-adult-male equivalent consumption of household $h$ in month $t, \widetilde{y}_{t}^{h}$ is (per-adult-equivalent) household income at time $t$, and $M D_{t}$ is a month dummy, that equals one for observations at time $t$, zero otherwise. The coefficient $\phi_{t}$ captures $\frac{1}{\sigma} \kappa_{t}$ from equation (1), which is proportional to a measure of the aggregate resource constraint at date $t$. The

error term $\varepsilon_{t}^{h}$ is assumed to be uncorrelated with the right hand side variables and to be mean zero. We assume the following covariance structure:

1. $\tau_{h t}^{2} \equiv \operatorname{Var}\left(\varepsilon_{t}^{h}\right)=\tau_{h}^{2} \quad \forall h, t ;$

2. $\tau_{h, t s} \equiv \operatorname{Cov}\left(\varepsilon_{t}^{h}, \varepsilon_{s}^{h}\right)=0 \quad \forall h, t \neq s$;

3. $\tau_{h k, t s} \equiv \operatorname{Cov}\left(\varepsilon_{t}^{h}, \varepsilon_{s}^{k}\right)=0 \quad \forall h \neq k, t \neq s$;

4. $\tau_{h k, t} \equiv \operatorname{Cov}\left(\varepsilon_{t}^{h}, \varepsilon_{t}^{k}\right)=0 \quad \forall t, h \neq k$.

The first assumption on heteroskedasticity is motivated by the results of several tests (such as the White general test and the Glesjer test based on the regression of the squared residuals on several household variables). Intuitively, it seems reasonable to allow the variance of the residuals to vary across households, since they have very different sizes, landholdings, consumption and income levels. The other assumptions are quite standard. We have tested for the presence of contemporaneous correlation across households using a variety of methods, and we find very little evidence, if any, of such correlation. We estimate (2) via FGLS, postulating that the individual household variance depends on several observable characteristics (such as landholdings or household size) in the following way:

$$
\tau_{h}^{2}=\tau^{2} \cdot \exp \left(\beta^{\prime} z_{h}\right)
$$

The regression equation (2) has been estimated numerous times in the literature on efficient risk sharing, for the special case in which $\alpha^{h}=\alpha$ for 
all $h$. Under the null hypothesis of full risk sharing in the village as a whole, equation (1) implies that $\alpha$ must be equal to zero. A significantly positive estimated coefficient $\widehat{\alpha}$ implies that the full risk-sharing hypothesis can be rejected for the village as a whole. Both villages in our dataset fail the full risk sharing test. For village $A, \widehat{\alpha}=0.0366$ (with a $p$-value of 0.005 ) and for village $B, \widehat{\alpha}=0.0299$ (with a $p$-value of 0.019 ).

For this paper we are interested in identifying specific households for which the implications of full risk-sharing models are rejected. So we estimate a separate $\alpha^{h}$ parameter for each household $h$. The baseline regression (2) is estimated separately for each village. The distribution of the estimates $\widehat{\alpha}^{h}$ are depicted in Figure 1. Nineteen households in village $A$ and 18 in village $B$ had positive and significant $\widehat{\alpha}^{h}$ using a $10 \%$ statistical significance level. ${ }^{11}$ The mean of the $\widehat{\alpha}^{h}$ estimates is 0.11 in village $A$ and 0.19 in village $B$.

The theoretical framework only offers a test of whether full risk sharing holds for a given household. To interpret the size of a significantly positive vulnerability coefficient, we consider autarky with limited savings possibilities as an alternative to the full risk sharing model. Under this alternative, $\alpha^{h}$ would be positive. As the household moves from full risk sharing to autarky, its $\alpha^{h}$ parameter will increase. ${ }^{12}$ Our baseline measure of vulnerability therefore is the estimated $\widehat{\alpha}^{h}$.

One may be concerned that the observed income fluctuations $\Delta \widetilde{y}_{t}^{h}$ may just reflect seasonal variations that affect the village as a whole (such as planting and harvest, rainy and dry seasons), and not household-specific shocks. But since such village-wide shocks are controlled for by the month dummy in the baseline regression (2), our $\widehat{\alpha}^{h}$ estimates detect responses of household consumption to household-specific shocks controlling for villagewide fluctuations. Further, there is substantial household specific (and hence insurable) risk in these economies. The deviations of household income from the village average are largely uncorrelated across households.

So far we have restricted all agents to have the same coefficient of absolute risk aversion $\sigma$. Our vulnerability estimates from regression (2) may be biased as a consequence. In particular, our $\widehat{\alpha}^{h}$ estimates may simply reflect individual differences in the attitude towards risk: a less risk averse household

\footnotetext{
${ }^{11}$ These numbers fall to 14 and 10 respectively, using a $5 \%$ significance level.

${ }^{12}$ Roughly one quarter of the estimated parameters are negative, but fewer than $6 \%$ of the total are negative at the $10 \%$ level. A couple of households in either village have an estimated vulnerability parameter larger than one. This is presumably because of measurement error.
} 
may be associated with a higher $\widehat{\alpha}^{h}$, whereas a more risk averse household may exhibit a lower $\widehat{\alpha}^{h}$. If some agents were more or less risk averse than others, with $\sigma^{h}$ denoting household $h$ 's degree of risk aversion, then equation (1) would become (ignoring the preference shock term for simplicity):

$$
\Delta\left(\frac{c_{t}^{h}}{n_{t}^{h}}\right)=-\frac{1}{\sigma^{h}} \kappa_{t}
$$

Suppose the true model were equation (3) but we estimate regression (2) instead. Then $\widehat{\phi}_{t}$ is an estimate of $-\bar{\nu} \kappa_{t}\left(\right.$ where $\bar{\nu}=\frac{1}{N} \sum_{h} \nu_{h}$ and $\left.\nu_{h} \equiv \frac{1}{\sigma^{h}}\right)$, and we have to evaluate the possibility that omitting the term $\left(\nu_{h}-\bar{\nu}\right) \kappa_{t}$ may bias our $\widehat{\alpha}^{h}$ estimates. Suppose we assume that $\nu_{h}$ is uncorrelated with $\Delta \widetilde{y}_{t}^{h}$, since the latter reflects idiosyncratic shocks that hit household $h$ which should be independent of that household's degree of risk aversion. That implies our $\widehat{\alpha}^{h}$ estimates from regression (2) will be biased only if there is a non zero correlation between $\Delta \widetilde{y}_{t}^{h}$ and $\kappa_{t}$, i.e. between changes in individual income and changes in the aggregate resource constraint over time. We proxy for $\kappa_{t}$ using the change in aggregate consumption. In the data, the correlation between changes in household income and changes in aggregate consumption is negligible and statistically insignificant for both villages (0.009 in village $A$ and -0.025 in village $B)$. Therefore differences in risk aversion will not bias our vulnerability estimates.

\subsection{Robustness}

We estimate several alternatives to the baseline vulnerability measure for each household:

1. Truncated. The first round of data collected in both villages is more susceptible to measurement error than subsequent rounds because the enumerators did not have a starting inventory of household grain and foodstuff to go by. Therefore we estimate $\alpha^{h}$ parameters excluding the first round of data.

2. Medical Expenses. The baseline regression model (2) assumes that preference shocks are uncorrelated with the other covariates. We also estimate a version of equation (1) where household specific medical expenditures $X_{t}^{h}$ in each period are used to proxy for the preference $\operatorname{shock} \zeta_{t}^{h}$ :

$$
\Delta \widetilde{c}_{t}^{h}=\alpha^{h} \Delta \widetilde{y}_{t}^{h}+\phi_{t} \cdot M D_{t}+\delta X_{t}^{h}+\varepsilon_{t}^{h}
$$


Sickness shocks can reduce a household's desire to consume, for instance, and can be correlated with income shocks.

3. Female Headship. The baseline regression equation (2) assumes common risk aversion. While we do not have the degrees of freedom necessary to directly estimate a household specific risk aversion coefficient, it is possible to allow the coefficient of absolute risk aversion to vary across groups. Female headship is associated with higher vulnerability in regressions of our baseline vulnerability measure on household characteristics. ${ }^{13}$ Therefore, it may be the case that female headed households are more risk averse than male headed households. A version of risk sharing implication (1) allowing for the coefficient of absolute risk aversion to differ across female and male headed households is

$$
\Delta\left(\frac{c_{t}^{h}}{n_{t}^{h}}\right)=-\frac{1}{\sigma^{F}} \kappa_{t}-\frac{1}{\sigma^{F}} \triangle \ln \zeta_{t}^{h}
$$

where $F$ is a Household Dummy that is equal to one if household $h$ is a female headed and zero otherwise. Therefore assuming, as before, that preference shocks can be treated as mean zero error terms that are uncorrelated with the other regressor, we also estimate the following version of the model:

$$
\Delta \widetilde{c}_{t}^{h}=\alpha^{h} \Delta \widetilde{y}_{t}^{h}+\phi_{t} \cdot M D_{t}+\phi_{F t} \cdot M D_{t} \cdot F+\varepsilon_{t}^{h}
$$

Thus we estimate a $\phi_{t}$ parameter for male headed households and a $\phi_{t}+\phi_{1 t}$ parameter for female headed households to reflect possible differences in risk aversion between the two.

4. Common Components. Measurement error that is common to consumption and income would bias our vulnerability estimate in equation (2). There are components of consumption (such as net meals received as wages and own produce consumed) that are also included as income. So we exclude these common components from the measure of income in our estimation of household vulnerability.

\footnotetext{
${ }^{13}$ Vulnerability is more elusive than poverty. The adjusted $R^{2}$ from regressions of vulnerability on household characteristics were much lower than the adjusted $R^{2}$ from regressions of average household all consumption on household characteristics. Further, only female headship in the pooled regression and in the village $B$ regression was significantly negative, by itself and with controls for other household characteristics.
} 
5. Stronger Definition. Our baseline vulnerability measure identifies a household as vulnerable even if it achieves the "average" level of vulnerability for the village as a whole. A stronger definition of vulnerability would only consider those households vulnerable who achieve less insurance than the average in the village. So we construct the following measure from the baseline: vulnerability is $\widehat{\alpha}^{h}$ if $\widehat{\alpha}^{h}>\widehat{\alpha}$ where $\widehat{\alpha}$ is the village vulnerability co-efficient (section 3.2), and vulnerability is 0 otherwise.

6. CRRA utility. To check if our measure of vulnerability is robust to the choice of utility function, we use a constant relative risk aversion (CRRA) utility specification,

$$
u^{h}\left(c_{t}^{h}\right)=\frac{1}{1-\gamma} \zeta_{t}^{h} n_{t}^{h}\left[\left(\frac{c_{t}^{h}}{n_{t}^{h}}\right)^{1-\gamma}\right],
$$

to derive the counterpart to equation (1):

$$
\Delta \ln \left(\frac{c_{t}^{h}}{n_{t}^{h}}\right)=-\frac{1}{\gamma} \kappa_{t}-\frac{1}{\gamma} \Delta \ln \zeta_{t}^{h}
$$

We estimate the following regression:

$$
\Delta \ln \widetilde{c}_{t}^{h}=\alpha^{h} \Delta \ln \widetilde{R}_{t}^{h}+\phi_{t} \cdot M D_{t}+\varepsilon_{t}^{h}
$$

where $\widetilde{R}_{t}^{h}$ represents per-adult-equivalent revenues for household $h$ at month $t$. We use revenues instead of income because the latter can sometimes take negative values, while the former cannot. Revenues proxy for idiosyncratic risk. The distribution of the $\widehat{\alpha}^{h}$ estimates are shown in Figure 1. Twentysix households had significantly positive $\widehat{\alpha}^{h}$ estimates in village $A$ and 29 households had significantly positive $\widehat{\alpha}^{h}$ estimates in village $B$.

Though these six alternative measures of vulnerability are either derived from different specifications of the baseline model or attempt to control for measurement error, it is reassuring that the identity of households that have significantly positive $\widehat{\alpha}^{h}$ estimates remains stable across the alternatives. With the baseline measure a total of 37 households in both villages have positive and significant $\widehat{\alpha}^{h}$ estimates (at the $10 \%$ significance level). With 
the female headship measure, 37 households have positive and significant $\widehat{\alpha}^{h}$ estimates, and only 2 of those households did not have positive and significant $\widehat{\alpha}^{h}$ estimates in the baseline. With the common components measure, 27 households had positive and significant $\widehat{\alpha}^{h}$ estimates, and only 3 of those households did not have positive and significant $\widehat{\alpha}^{h}$ estimates in the baseline. The pattern is similar for the other alternative vulnerability measures. Consequently we are confident that the baseline vulnerability measure is fairly robust. In what follows, we will present results first using the baseline measure, and then using the alternative measures as a cross-check.

\subsection{Vulnerability, Variability and Poverty}

As one would perhaps expect, poorer households tend to be more vulnerable than richer households in our data. Vulnerability is significantly negatively correlated with consumption using the pooled data and in village $B$ (Table 5). This finding is stable across all the alternative vulnerability measures, except for CRRA measure where the correlation is negative but not significant. The same pattern emerges from a comparison of the average vulnerability of households below the poverty line with those above the poverty line in Table 6. Households below the poverty line have significantly higher average vulnerability than those above the poverty line for the baseline and half the alternative vulnerability measures using the pooled data, and for the baseline and all but one of the alternative vulnerability measures in village $B{ }^{14}$

Our measure of vulnerability is quite distinct from measures of consumption variability, such as the coefficient of variation (CV) of consumption or the variance of log consumption. ${ }^{15}$ The baseline and most alternative measures of vulnerability are not significantly correlated with either of the two measures of consumption variability (Table 5). Though poor households tend to be more vulnerable than the rich, rich households have more variable consumption than the poor. Household consumption is positively correlated with the $\mathrm{CV}$ of consumption using the pooled data and in village $A$ for food consumption (Table 5). Households below the poverty line have a significantly lower $\mathrm{CV}$ of consumption than those above the poverty line in each village (Table 6). Households below the poverty line also have a significantly lower variance of log consumption than households above the

\footnotetext{
${ }^{14}$ Jalan and Ravallion (1999) also find that the poor are significantly more vulnerable than the rich in rural China.

${ }^{15}$ Morduch (1998) uses the latter as a proxy for household vulnerability.
} 
poverty line using the pooled data (Table 6). In addition, while consumption variability may just capture differences in risk aversion across households, our vulnerability measure is unbiased even when some households are more risk averse than others, provided the degree of risk aversion is uncorrelated with shocks to household income (Section 3.2). Consequently for the rest of the paper we will be concerned with vulnerability and not with consumption variability.

\section{Results}

In this Section we test if households that joined microcredit programs by 1995 were poorer and more vulnerable in 1991 - 92 than households that did not join microcredit programs by 1995 . We do this by comparing average consumption and average vulnerability of members with non-members, testing whether the distribution of consumption and vulnerability of members first order stochastically dominates that of non-members, and by conducting probit regressions of microcredit membership on consumption, vulnerability and household characteristics.

\subsection{Poverty}

There is clear evidence that households that joined microcredit programs by 1995 were poorer in 1991 - 92 than those that did not join. The Cumulative Distribution Functions (CDFs) of average monthly consumption and income for microcredit members and non-members are shown in Figure 2. In both villages, and more so in village $B$, the distribution for non-members is shifted to the right. The average monthly consumption for members is significantly lower than that of non-members using the pooled data, and in both villages separately (Table 6 ). In village $A$ average monthly all consumption is 36 taka (approximately $\$ 1$ ) lower for members, which is10 percent of the village average monthly consumption. In village $B$ average monthly all consumption is 88 taka (approximately $\$ 2$ ) lower for members, which is 20 percent of the village average monthly consumption. Correlations between average monthly consumption and membership are also significantly negative using the pooled data and in village $B$ and negative but barely insignificant in village $A$ (Table 5).

In addition to just looking at specific moments of the distribution of 
consumption of members and non-members, we also use a non parametric test to check if the distribution of average monthly consumption for nonmembers first order dominates that for members. This test is based on Anderson (1996) and is described in more detail in the appendix. The results in Table 3 show that the distribution of consumption for non-members significantly first order stochastically dominates the distribution for members using the pooled data and in village $B$. The test of first order stochastic dominance goes in the same direction, but is barely insignificant, in village $A$. Thus we have a strong indication that members are poorer than nonmembers, since first order stochastic dominance implies both second and third order dominance.

Another way of evaluating the success of microcredit programs in reaching the poor is by using the poverty line. The proportion of microcredit members below the poverty line is 79 percent in village $A$ and 74 percent in village $B$, which is significantly higher than the proportion of non-members below the poverty line in both villages (Table 6). The proportion of microcredit members below the poverty line is also higher than the village averages, the Rajshahi district average and the national average of 47 percent (see Section 2). Therefore, the probability that a household was below the poverty line when it received a loan is substantially higher than the probability of a randomly picked Bangladeshi household being below the poverty line.

A probit regression in table 7 shows that a 100 taka or 24 percent decrease in monthly consumption at the mean gives a household a 6 or 7 percent higher probability of receiving a loan on average. This is statistically significant using the pooled data and in village $B$ conditional on vulnerability (column 4) and controlling for other household characteristics (column 6). This is significant for village $A$ controlling for vulnerability (column 4) and significant at the $11 \%$ level controlling for other household characteristics (column 6).

Since one-third of the households that eventually became microcredit members in village $B$ joined before the end of the twelve rounds of data collection in 1992, there is the possibility that the loans they received may have affected the consumption of those households, and thus could bias our results. Provided loans have a non-negative impact on household consumption, however, such a bias will only strengthen our finding that microcredit reaches the poor. Our results may therefore underestimate microcredit's effectiveness at reaching the poor in village $B$.

Finally notice that having more arable land is not significantly associated 
with a lower probability of joining a microcredit program (Table 7 column 3 ). So that though microcredit does reach the consumption-poor there is no evidence that it reaches the relatively landless. ${ }^{16}$

\subsection{Vulnerability}

There is weak evidence that households that joined microcredit programs by 1995 were more vulnerable in 1991 - 92 than those that did not join. The Cumulative Distribution Functions (CDFs) of vulnerability for microcredit members and non-members are shown in Figure 2. Notice that though members appear to be more vulnerable in village $B$, non-members appear to be more vulnerable in village $A$. The average vulnerability of members is significantly higher than that of non-members in village $B$ but not in the pooled data (Table 6). This is robust to all alternative vulnerability measures except for the Common measure, where it is barely insignificant. Correlations between vulnerability and membership are also significantly negative only in village $B$ but not in the pooled data (Table 5 ), and this finding is robust to alternative vulnerability measures. The results from the non-parametric tests in Table 4 show that the distribution of vulnerability for members significantly first order stochastically dominates the distribution for non-members using the pooled data and in village $B$.

The probit regression in table 7 yields the same pattern across the two villages (column 1) and again it is robust to most alternative vulnerability measures. Raising vulnerability by 0.2 at the mean raises the probability of being a microcredit member by about 3 percent in village $B$. Interestingly, vulnerability does not significantly increase a household's probability of joining if we control for poverty (column 4) and other household characteristics (column 6). This gives a potential explanation for the differences across villages: since village $B$ is richer than village $A$, vulnerable households may be more likely to join in village $B$ only because they are not as poor.

This result is subject to the following caveat. It seems reasonable to suppose that microcredit membership either decreases a household's vulnerability or leaves it unaltered. Since a third of the microcredit members in

\footnotetext{
${ }^{16}$ Only households with less than half an acre of cultivated land are typically eligible to join Grameen, BRAC and ASA. Table 3 shows that over half the households that joined microcredit programs in 1995 did not meet this eligibility criterion in 1991. Since some of these households may have split or sold land to meet the landholding criterion, this may be an overestimate of mistargeting.
} 
village $B$ joined Grameen before the end of the twelve rounds of data collection in 1992, these households may appear less vulnerable than they were before joining Grameen. Consequently we may underestimate microcredit's effectiveness at reaching the vulnerable in village $B$.

\subsection{Interaction}

Finally, we wish to check if vulnerable households below the poverty line have a higher probability of joining microcredit programs than vulnerable households above the poverty line. We are particularly interested in this since the vulnerable poor are those that would likely gain the most from gaining access to smoothing devices, thus avoiding possible destitution. Therefore, we introduce an interaction term in the probit regression in Table 7 (column 5). The coefficient on the interaction term is insignificant using the pooled data and in village $B$. But interestingly, the interaction has a significantly negative coefficient in village $A$ (and the coefficient remains significantly negative when we replace the baseline vulnerability measure with the alternative vulnerability measures that use truncated data, control for medical expenses and exclude common components). For households that are below the poverty line in village $A$, raising vulnerability by 0.1 or 9 percent at the mean lowers the probability of joining a microcredit program by about 2.3 percent, and this is significant at the $10 \%$ level.

So microcredit does not reach the vulnerable poor in the relatively richer village $B$, and appears to exclude the vulnerable poor in the poorer village $A$. In other words, poor households that do join tend to have better access to insurance and smoothing devices than those who do not. The vulnerable poor may either choose not to join or they may be excluded by the microcredit program. There is some anecdotal evidence consistent with the latter. For instance, a bank officer told Todd (1996, p.173) that he was looking for borrowers that were "not hopeless." This suggests that subsidized loans may not be the appropriate strategy to reach the vulnerable poor, because of their potentially higher default risk.

Microcredit's success at reaching the poor is robust to introducing the interaction term. Households below the poverty line have a 19 percent higher chance of joining a microcredit program using the pooled data (Table 7, column 5). This coefficient remains significantly positive when we use alternative vulnerability measures instead of the baseline. 


\section{Conclusions}

This paper uses panel data from two Bangladeshi villages to test if microcredit reaches the poor and vulnerable. This analysis is possible due to the convenient timing of data collection. Households were extensively surveyed in 1991 - 92, when microcredit programs had only a small presence in the study villages. Households were subsequently resurveyed in 1995 by which time microcredit programs had firmly established themselves.

This paper studies the interaction between microcredit selection and the vulnerability of rural households. Vulnerability refers to the inability of households to insure against idiosyncratic risks, and it is distinct from measures of consumption variability. It provides an example of how an antipoverty program which is successful at reaching the poor may exclude the those most in need of assistance, the vulnerable poor. The forces that make some poor households vulnerable may also make them greater risks for microcredit providers, however. This may explain why microcredit programs are unsuccessful at reaching the vulnerable poor in these villages, and suggests that subsidized credit may have limits as an anti-poverty strategy. ${ }^{17}$

Our vulnerability estimates for instance are based on monthly data collected over 12 months. It would be interesting to see if estimates of household vulnerabilty are stable from year to year, or if some households are more vulnerable to annual income shocks than to monthly shocks. It would also be useful to know if microcredit's success at reaching the vulnerable poor depends on village characteristics, such as average village poverty or vulnerability. How does the process of forming borrower groups affect the likelihood that the vulnerable poor join microcredit programs? Do relatively poor and vulnerable households had higher default rates after they join microcredit programs? We leave these questions for future research with more detailed data sets.

\footnotetext{
${ }^{17}$ Subsidized microcredit may need to be supplemented with grants that reach the vulnerable poor. Rai and Sjöström (2001) show giving both grants and subsidized loans is the efficient government intervention in a model where the poor are credit constrained.
} 


\section{Appendix: First Order Stochastic Domi- nance tests}

Suppose the cumulative distribution function of consumption for $N$ (for nonmembers) and $M$ (for members) is given by $F_{N}(c)$ and $F_{M}(c)$ respectively. Let $C$ be the range of consumption for both these distributions First order stochastic dominance of distribution $N$ over $M$ is equivalent to the condition:

$$
F_{N}(c) \leq F_{M}(c), F_{N}\left(c_{i}\right) \neq F_{M}\left(c_{i}\right) \text { for some } i, \forall c \in C \text {. }
$$

Anderson's (1996) test of first order stochastic dominance is quite straightforward to implement. The idea is to partition the combined sample for $N$ and $M$ into $k$ equal intervals and compute the empirical frequencies of the $N$ and $M$ samples in each interval: for example, $p_{i}^{N}=\frac{x_{i}^{N}}{n^{N}}, i=1, \ldots, k$, where $x_{i}^{N}$ is the number of observations in the $N$ sample that fall in interval $i$, and $n^{N}$ is the total number of observations in the $N$ sample. Let $I_{f}$ be a $k \times k$ lower-triangular matrix of ones. Since the cumulative distribution function at a point $j$ can be computed as $F\left(c_{j}\right)=\sum_{i=1}^{j} p_{i}$, a test of condition (7) translates into the following hypothesis test:

$$
H_{0}: I_{f}\left(p^{N}-p^{M}\right)=0 \text { against } H_{1}: I_{f}\left(p^{N}-p^{M}\right) \leq 0
$$

In particular, first order dominance of distribution $N$ over $M$ requires that no element of the vector $I_{f}\left(p^{N}-p^{M}\right)$ be significantly greater than zero, while at least one element is significantly negative. The test is symmetric, so first order dominance of distribution $M$ over $N$ requires that no element of the vector $I_{f}\left(p^{N}-p^{M}\right)$ be significantly negative, while at least one element is significantly positive. Finally, the test statistic $I_{f}\left(p^{N}-p^{M}\right)$ is asymptotically distributed as a $N\left(0, I_{f} V I_{f}^{\prime}\right)$ under the null hypothesis, where $V$ can be estimated using the empirical frequencies $p$ of the combined sample. See Anderson (1996) for the details. 


\section{References}

[1] Amin, S. 1998. "Family Structure and Change in Rural Bangladesh," Population Studies, 52, $201-213$.

[2] Anderson, G. 1996. "Nonparametric Tests of Stochastic Dominance in Income Distributions," Econometrica, 64,1183 - 1193.

[3] Deaton, A. 1997. The Analysis of Household Surveys: A Microeconometric Approach to Development Policy, (Johns Hopkins/World Bank).

[4] Jalan, J. and M. Ravallion 1999. "Are the Poor Less Well Insured? Evidence on Vulnerability to Income Risk in Rural China," Journal of Development Economics 58(1) : $61-81$.

[5] Morduch, J. 1998. "Does Microfinance Really Help the Poor? New Evidence from Flagship Programs in Bangladesh," mimeo, New York University

[6] Morduch, J. 1999. "The Microfinance Promise," Journal of Economic Literature, $37: 4$, December.

[7] Navajas, S. Meyer, C. Gonzales-Vega, M. Schreiner and J. RodriguezMeza, 1998. "Microcredit and the Poorest of the Poor: Theory and Evidence from Bolivia", mimeo, Ohio State University.

[8] New York Times, 1997. "Micro-Loans for the Very Poor," (editorial), February 16.

[9] Pitt, M. and S. Khandker. 1998a. "The Impact of Group Based Credit Programs on Poor Households in Bangladesh: Does the Gender of Participants Matter?," Journal of Political Economy, 106 : 5.

[10] Pitt, M. and S. Khandker 1998b. "Credit Programs for the Poor and Seasonality in Rural Bangladesh", mimeo, Brown University and World Bank.

[11] Rai, A. and T. Sjöström, 2001. "Grants Vs. Investment Subsidies." Harvard Center for International Development Working Paper. 
[12] Ravallion, M. and G. Datt, 1995. "Is Targeting Through a Work Requirement Efficient? Some Evidence from Rural India," in van de Walle, D. and K. Nead 1995). Public Spending and the Poor: Theory and Evidence, (Johns Hopkins University Press, Baltimore).

[13] Shams, K. 1992. "Designing Effective Credit Delivery System for the Poor: The Grameen Bank Experience," Grameen Bank, Dhaka.

[14] Todd, H. 1996. Women at the Center, Westview Press.

[15] Townsend, R. 1994. "Risk and Insurance in Village India," Econometrica, $62: 3,539-91$.

[16] Vogel, R. 1984. "The Effect of Subsidized Agricultural Credit on Income Distribution in Costa Rica," in Adams, D., D. Graham and J.D. von Pischke (1984). Undermining Rural Development with Cheap Credit, (Westview Press, Boulder).

[17] Wodon, Q. 1997. "Food Energy Intake and the Cost of Basic Needs: Measuring Poverty in Bangladesh," Journal of Development Studies, $34(2): 66-101$.

[18] World Bank 2001. World Development Report on Poverty and Development, Washington DC, World Bank. 
TABLE 1

SUMMARY STATISTICS*

\begin{tabular}{|c|c|c|c|c|c|c|}
\hline & \multicolumn{3}{|c|}{$\begin{array}{c}\text { VILLAGE A } \\
\text { (112 Households) }\end{array}$} & \multicolumn{3}{|c|}{$\begin{array}{c}\text { VILLAGE B } \\
(117 \text { Households }) \\
\end{array}$} \\
\hline & Mean & Std. Dev. & $\mathrm{CV}$ & Mean & Std. Dev. & $\mathrm{CV}$ \\
\hline Food Consumption & 324.00 & 171.05 & 0.53 & 351.73 & 227.61 & 0.65 \\
\hline All Consumption & 388.38 & 210.35 & 0.54 & 466.93 & 308.29 & 0.66 \\
\hline All Income & 429.69 & 347.49 & 0.81 & 537.62 & 564.04 & 1.05 \\
\hline All Revenue & 537.23 & 467.85 & 0.87 & 681.84 & 713.47 & 1.05 \\
\hline Medical Expenditures & 36.06 & 50.37 & 1.40 & 57.56 & 77.20 & 1.34 \\
\hline Household Size & 4.64 & 2.43 & 0.52 & 4.60 & 2.02 & 0.44 \\
\hline Age of HH Head & 41.77 & 14.34 & 0.34 & 43.66 & 13.97 & 0.32 \\
\hline Number of children & 1.66 & 1.30 & 0.78 & 1.57 & 1.20 & 0.77 \\
\hline Number of Old People & 0.19 & 0.46 & 2.35 & 0.21 & 0.45 & 2.11 \\
\hline Agricultural Land & 904.99 & 2750.02 & 3.04 & 766.45 & 1980.07 & 2.58 \\
\hline
\end{tabular}

*All statistics are weighed to correctly reflect the proportion of female-headed households in the population.

*The first five variables are measured in units of 1992 taka per adult equivalent per month. Agricultural land is measured in decimals (100 decimals $=1$ acre $)$.

*Exchange Rate in 1992 was US \$1=38 taka. 
TABLE 2

HOUSEHOLD CATEGORIES AND MICROCREDIT MEMBERSHIP

\begin{tabular}{lcc}
\hline \hline & Village A & Village B \\
\hline Total Number of Sampled Households & 112 & 117 \\
Landless (arable land $<=0.5$ acres) & 42 & 47 \\
Landed & 70 & 70 \\
Female-headed & 24 & 31 \\
Male-headed & 88 & 86 \\
Uneducated Household Head & 71 & 71 \\
Educated Household Head & 41 & 46 \\
Members of Microcredit NGO & $38 *$ & $38 * *$ \\
Non-members & 74 & 79 \\
Members of ASA & 12 & 3 \\
Members of BRAC & 16 & 19 \\
Members of Grameen & 10 & 17 \\
\hline
\end{tabular}

*14 microcredit members were landless in 1992 in Village A.

**17 microcredit members were landless in 1992 in Village B.

In Village B, one $\mathrm{HH}$ is a member of both BRAC and Grameen. 
TABLE 3

POVERTY AND MICROCREDIT MEMBERSHIP

TEST OF STOCHASTIC DOMINANCE

\begin{tabular}{|c|c|c|c|c|c|c|c|}
\hline \multicolumn{3}{|c|}{ Pooled Data } & \multicolumn{2}{|c|}{ Village A } & \multicolumn{3}{|c|}{ Village B } \\
\hline $\begin{array}{l}\text { Members minus } \\
\text { Non-members }\end{array}$ & (t-statisti & & $\begin{array}{l}\text { Members minus } \\
\text { Non-members }\end{array}$ & (t-statistics) & $\begin{array}{l}\text { Members minus } \\
\text { Non-members }\end{array}$ & (t-statis & \\
\hline 0.0256 & 0.7547 & & -0.0154 & -0.4090 & 0.0803 & 1.5172 & $*$ \\
\hline 0.0825 & 1.3334 & & 0.0175 & 0.2315 & 0.1768 & 1.9994 & $* *$ \\
\hline 0.1911 & 2.7245 & $* *$ & 0.0665 & 0.6636 & 0.3131 & 3.1653 & $* * *$ \\
\hline 0.1819 & 2.9260 & $* * *$ & 0.1228 & 1.3485 & 0.2004 & 2.1735 & $* *$ \\
\hline 0.1081 & 2.0111 & $* *$ & 0.0892 & 1.2023 & 0.1889 & 2.1811 & $* *$ \\
\hline 0.0739 & 1.8470 & $* *$ & 0.0183 & 0.3170 & 0.1005 & 1.4370 & $*$ \\
\hline 0.0535 & 1.7661 & $*$ & 0.0417 & 1.2758 & 0.0762 & 1.4407 & $*$ \\
\hline 0.0533 & 2.0499 & $* *$ & 0.0278 & 1.0369 & 0.0897 & 1.9051 & $* *$ \\
\hline 0.0200 & 1.2411 & & 0.0139 & 0.7298 & 0.0385 & 1.2249 & \\
\hline
\end{tabular}

The columns report the differences between the CDF of Consumption for Members and Non-members, at several points. Under the null hypothesis that the two samples come from the same distribution, each term is distributed as a Student's $t$ with (here) 9 degrees of freedom.The t-statistics are in parentheses. The distribution for Members first order dominates that for Non-members if no term is significantly greater than zero while at least one is significantly negative. Likewise, dominance of Non-members over Members requires than no term be significantly negative while at least one is significantly positive.

* Statistically significant at $10 \%$ level.

**Statistically significant at 5\% level.

***Statistically significant at $1 \%$ level. 
TABLE 4

VULNERABILITY AND MICROCREDIT MEMBERSHIP TEST OF STOCHASTIC DOMINANCE

\begin{tabular}{|c|c|c|c|c|c|c|}
\hline \multicolumn{2}{|c|}{ Pooled Data } & \multicolumn{2}{|c|}{ Village A } & \multicolumn{3}{|c|}{ Village B } \\
\hline $\begin{array}{l}\text { Members minus } \\
\text { Non-members }\end{array}$ & (t-statistics) & $\begin{array}{c}\text { Members minus } \\
\text { Non-members }\end{array}$ & (t-statistics) & $\begin{array}{l}\text { Members minus } \\
\text { Non-members }\end{array}$ & (t-statistics & \\
\hline-0.0200 & -1.2411 & -0.0139 & -0.7298 & -0.0256 & -0.9957 & \\
\hline-0.0204 & -0.7392 & -0.0015 & -0.0448 & -0.0250 & -0.6214 & \\
\hline-0.0160 & -0.2794 & -0.0154 & -0.4090 & -0.0209 & -0.2652 & \\
\hline 0.0021 & 0.0409 & -0.0395 & -0.4634 & -0.0965 & -1.2233 & \\
\hline 0.0005 & 0.0191 & 0.1045 & 1.3033 & -0.0405 & -0.9241 & \\
\hline 0.0004 & 0.0155 & 0.0431 & 0.9472 & -0.0270 & -0.7477 & \\
\hline-0.0130 & -0.6993 & 0.0417 & 1.2758 & -0.0398 & -1.2679 & \\
\hline-0.0132 & -1.4080 & 0.0278 & 1.0369 & -0.0263 & -1.4389 & $*$ \\
\hline-0.0132 & -1.4080 & 0.0139 & 0.7298 & -0.0263 & -1.4389 & $*$ \\
\hline
\end{tabular}

The columns report the differences between the CDF of Vulnerability for Members and Non-members, at several points. Under the null hypothesis that the two samples come from the same distribution, each term is distributed as a Student's $t$ with (here) 9 degrees of freedom. The t-statistics are in parentheses. The distribution for Members first order dominates that for Non-members if no term is significantly greater than zero while at least one is significantly negative. Likewise, dominance of Non-members over Members requires than no term be significantly negative while at least one is significantly positive.

* Statistically significant at $10 \%$ level.

**Statistically significant at 5\% level.

$* * *$ Statistically significant at $1 \%$ level. 
TABLE 5

CORRELATIONS BETWEEN VULNERABILITY, VARIABILITY, CONSUMPTION, AND MICROCREDIT MEMBERSHIP

\section{Pooled Data}

\begin{tabular}{l|cc|cc|c}
\hline \hline & C.V.(Cons.) & $\mathrm{V}(\log ($ Cons.) $)$ & All Cons. & Food Cons. & MC Member. \\
\hline Vuln. (Baseline) & $\mathbf{- 0 . 0 5}$ & $\mathbf{- 0 . 0 4}$ & $\mathbf{- 0 . 1 2} * *$ & $\mathbf{- 0 . 1 4} * *$ & $\mathbf{0 . 0 7}$ \\
Vuln. (Truncated) & 0.00 & 0.05 & $-0.14 * *$ & $-0.16 * * *$ & 0.04 \\
Vuln. (Med. Exp) & -0.05 & -0.04 & $-0.13 * *$ & $-0.15 * *$ & 0.07 \\
Vuln. (Female) & -0.04 & -0.03 & $-0.12 * *$ & $-0.14 * *$ & 0.08 \\
Vuln. (Common) & 0.02 & 0.06 & $-0.10 *$ & $-0.11 * *$ & 0.03 \\
Vuln. (Strong) & $0.15 * *$ & $0.11 * *$ & $-0.15 * *$ & $-0.16 * * *$ & 0.05 \\
Vuln. (CRRA) & $0.10 *$ & $0.09 *$ & -0.03 & -0.03 & 0.05 \\
\hline C.V.(Cons) & 1.00 & $0.82 * * *$ & $0.10 *$ & $0.09 *$ & -0.03 \\
Var(log(Cons)) & & 1.00 & 0.02 & -0.03 & -0.02 \\
\hline Avg. All Cons. & & & 1.00 & $0.94 * * *$ & $-0.21 * * *$ \\
Avg. Food Cons. & & & & 1.00 & $-0.20 * * *$ \\
\hline
\end{tabular}

\section{Village $A$}

\begin{tabular}{l|cc|cc|c}
\hline \hline & C.V.(Cons.) & V(log(Cons.)) & All Cons. & Food Cons. & MC Member. \\
\hline Vuln. (Baseline) & $\mathbf{- 0 . 0 5}$ & $\mathbf{- 0 . 0 4}$ & $\mathbf{0 . 0 1}$ & $\mathbf{0 . 0 3}$ & $\mathbf{- 0 . 0 7}$ \\
Vuln. (Truncated) & 0.11 & $0.15 *$ & -0.08 & -0.06 & -0.08 \\
Vuln. (Med. Exp) & -0.05 & -0.03 & 0.01 & 0.03 & -0.06 \\
Vuln. (Female) & -0.04 & -0.01 & 0.03 & 0.05 & -0.04 \\
Vuln. (Common) & 0.09 & $0.14 *$ & -0.11 & -0.10 & -0.08 \\
Vuln. (Strong) & $0.17 * *$ & $0.16 * *$ & 0.00 & 0.03 & -0.11 \\
Vuln. (CRRA) & 0.05 & 0.06 & 0.07 & 0.10 & -0.10 \\
\hline C.V.(Cons) & 1.00 & $0.82 * * *$ & 0.11 & $0.13 *$ & $-0.20 * *$ \\
Var(log(Cons)) & & 1.00 & -0.02 & -0.03 & $-0.22 * *$ \\
\hline Avg. All Cons. & & & 1.00 & $0.95 * * *$ & -0.12 \\
Avg. Food Cons. & & & & 1.00 & -0.11 \\
\hline
\end{tabular}

\section{Village B}

\begin{tabular}{l|cc|cc|c}
\hline \hline & C.V.(Cons.) & $\mathrm{V}(\log ($ Cons.) & All Cons. & Food Cons. & MC Member. \\
\hline Vuln. (Baseline) & $\mathbf{- 0 . 0 5}$ & $\mathbf{- 0 . 0 4}$ & $\mathbf{- 0 . 2 1} * *$ & $\mathbf{- 0 . 2 4} * * *$ & $\mathbf{0 . 1 6} * *$ \\
Vuln. (Truncated) & -0.10 & -0.06 & $-0.21 * *$ & $-0.24 * * *$ & $0.17 * *$ \\
Vuln. (Med. Exp) & -0.05 & -0.04 & $-0.22 * * *$ & $-0.25 * * *$ & $0.16 * *$ \\
Vuln. (Female) & -0.04 & -0.04 & $-0.22 * * *$ & $-0.26 * * *$ & $0.17 * *$ \\
Vuln. (Common) & -0.04 & 0.00 & -0.10 & $-0.12 *$ & $0.13 *$ \\
Vuln. (Strong) & $0.16 * *$ & 0.09 & $-0.25 * * *$ & $-0.26 * * *$ & $0.16 * *$ \\
Vuln. (CRRA) & $0.14 *$ & 0.11 & -0.10 & -0.11 & $0.14 *$ \\
\hline C.V.(Cons) & 1.00 & $0.81 * * *$ & 0.09 & 0.06 & $0.14 *$ \\
Var(log(Cons)) & & 1.00 & 0.05 & -0.03 & $0.17 * *$ \\
\hline Avg. All Cons. & & & 1.00 & $0.95 * * *$ & $-0.27 * * *$ \\
Avg. Food Cons. & & & & $-0.28 * * *$ \\
\hline \hline
\end{tabular}

Each cell reports the correlation coefficient between the row and the column variables.

* Statistically significant at $10 \%$ level.

**Statistically significant at 5\% level.

$* * *$ Statistically significant at $1 \%$ level. 
TABLE 6

VULNERABILITY, VARIABILITY, CONSUMPTION BY

POVERTY STATUS AND MICROCREDIT MEMBERSHIP

\section{Pooled Data}

\begin{tabular}{l|cccccc}
\hline \hline & Poor & Non Poor & $p$-value & Member & Non Mem. & $p$-value \\
\hline Vuln. (Baseline) & $\mathbf{0 . 1 8}$ & $\mathbf{0 . 1 0}$ & $\mathbf{0 . 0 9 3}$ & $\mathbf{0 . 2 0}$ & $\mathbf{0 . 1 3}$ & $\mathbf{0 . 1 6 8}$ \\
Vuln. (Truncated) & 0.21 & 0.10 & 0.059 & 0.20 & 0.15 & 0.257 \\
Vuln. (Med. Exp) & 0.18 & 0.10 & 0.082 & 0.20 & 0.13 & 0.158 \\
Vuln. (Female) & 0.19 & 0.11 & 0.112 & 0.21 & 0.13 & 0.125 \\
Vuln. (Common) & 0.09 & 0.08 & 0.443 & 0.12 & 0.07 & 0.304 \\
Vuln. (Strong) & 0.25 & 0.18 & 0.058 & 0.25 & 0.21 & 0.249 \\
Vuln. (CRRA) & 0.19 & 0.14 & 0.153 & 0.19 & 0.16 & 0.256 \\
\hline C.V.(Cons) & 0.43 & 0.52 & 0.004 & 0.46 & 0.47 & 0.336 \\
Var(log(Cons)) & 0.19 & 0.23 & 0.068 & 0.20 & 0.21 & 0.387 \\
\hline \% Below Pov. Line & & & & 76.30 & 56.70 & 0.000 \\
Avg. All Cons. & & & 361.20 & 440.18 & 0.000 \\
Avg. Food Cons. & & & 287.55 & 346.59 & 0.000 \\
\hline
\end{tabular}

\section{Village $A$}

\begin{tabular}{l|cccccc}
\hline \hline & Poor & Non Poor & $p$-value & Member & Non Mem. & $p$-value \\
\hline Vuln. (Baseline) & $\mathbf{0 . 1 1}$ & $\mathbf{0 . 1 2}$ & $\mathbf{0 . 4 5 4}$ & $\mathbf{0 . 0 8}$ & $\mathbf{0 . 1 3}$ & $\mathbf{0 . 2 1 4}$ \\
Vuln. (Truncated) & 0.17 & 0.11 & 0.287 & 0.09 & 0.18 & 0.163 \\
Vuln. (Med. Exp) & 0.11 & 0.12 & 0.458 & 0.08 & 0.13 & 0.228 \\
Vuln. (Female) & 0.11 & 0.14 & 0.371 & 0.09 & 0.13 & 0.313 \\
Vuln. (Common) & 0.11 & 0.08 & 0.398 & 0.03 & 0.13 & 0.145 \\
Vuln. (Strong) & 0.17 & 0.19 & 0.431 & 0.13 & 0.20 & 0.076 \\
Vuln. (CRRA) & 0.13 & 0.15 & 0.284 & 0.10 & 0.15 & 0.154 \\
\hline C.V.(Cons) & 0.43 & 0.54 & 0.037 & 0.40 & 0.50 & 0.006 \\
Var(log(Cons)) & 0.20 & 0.23 & 0.171 & 0.16 & 0.23 & 0.006 \\
\hline \% Below Pov. Line & & & & 78.90 & 65.30 & 0.057 \\
Avg. All Cons. & & & & 353.78 & 389.80 & 0.084 \\
Avg. Food Cons. & & & & 299.34 & 325.74 & 0.112 \\
\hline
\end{tabular}

\section{Village $B$}

\begin{tabular}{l|cccccc}
\hline \hline & Poor & Non Poor & $p$-value & Member & Non Mem. & $p$-value \\
\hline Vuln. (Baseline) & $\mathbf{0 . 2 7}$ & $\mathbf{0 . 0 9}$ & $\mathbf{0 . 0 3 1}$ & $\mathbf{0 . 3 2}$ & $\mathbf{0 . 1 3}$ & $\mathbf{0 . 0 6 3}$ \\
Vuln. (Truncated) & 0.25 & 0.09 & 0.047 & 0.31 & 0.12 & 0.057 \\
Vuln. (Med. Exp) & 0.27 & 0.09 & 0.026 & 0.32 & 0.13 & 0.061 \\
Vuln. (Female) & 0.28 & 0.09 & 0.026 & 0.33 & 0.14 & 0.055 \\
Vuln. (Common) & 0.08 & 0.08 & 0.486 & 0.21 & 0.02 & 0.109 \\
Vuln. (Strong) & 0.35 & 0.17 & 0.012 & 0.37 & 0.22 & 0.084 \\
Vuln. (CRRA) & 0.26 & 0.13 & 0.039 & 0.28 & 0.17 & 0.081 \\
\hline C.V.(Cons) & 0.43 & 0.52 & 0.029 & 0.51 & 0.44 & 0.060 \\
Var(log(Cons)) & 0.19 & 0.22 & 0.121 & 0.24 & 0.19 & 0.035 \\
\hline \% Below Pov. Line & & & 73.70 & 48.70 & 0.003 \\
Avg. All Cons. & & & 368.62 & 486.69 & 0.000 \\
Avg. Food Cons. & & & 275.76 & 365.83 & 0.000 \\
\hline \hline
\end{tabular}

Each cell reports the average of the row variable, by Poor (Non Poor) or by Member (Non Member).

A household is Poor if it is below the poverty line, and Non Poor otherwise.

The p-value refers to the test that the difference between Poor and Non Poor (or Member and Non Member) is equal to zero. 
TABLE 7

PROBIT REGR. OF MICROCREDIT MEMBERSHIP ON VULNERABILITY, CONSUMPTION AND HH CHARACTERISTICS

\begin{tabular}{|c|c|c|c|c|c|c|}
\hline \multirow[b]{3}{*}{ Vulnerability } & \multicolumn{6}{|c|}{ POOLED DATA } \\
\hline & $(1)^{*}$ & $(2)^{*}$ & $(3)^{*}$ & $(4)^{*}$ & $(5)^{*}$ & $(6)^{*}$ \\
\hline & $0.0693 \quad(0.318)$ & & & $0.0425(0.544)$ & $0.1059 \quad(0.518)$ & $0.0561 \quad(0.403)$ \\
\hline Avg. Cons. & & $-0.0007 \quad(0.000)$ & & $-0.0007 \quad(0.000)$ & & $-0.0006 \quad(0.004)$ \\
\hline Agric. Land & & & $-0.00004 \quad(0.127)$ & & & $-0.0000 \quad(0.819)$ \\
\hline Poor (Dummy) & & & & & $0.1920 \quad(0.007)$ & \\
\hline Vuln. x Poor & & & & & $-0.0620 \quad(0.732)$ & \\
\hline Female headed & & & & & & $0.0489 \quad(0.633)$ \\
\hline Age of Head & & & & & & $-0.0087 \quad(0.009)$ \\
\hline Household Size & & & & & & $0.0183 \quad(0.550)$ \\
\hline HH Structure & & & & & & $0.0012 \quad(0.989)$ \\
\hline Uneduc. Head & & & & & & $0.0598 \quad(0.406)$ \\
\hline \# Old in $\mathrm{HH}$ & & & & & & $0.0103 \quad(0.905)$ \\
\hline \# Children in $\mathrm{HH}$ & & & & & & $-0.0296 \quad(0.432)$ \\
\hline Pseudo $\mathrm{R}^{\wedge} 2$ & 0.0032 & 0.0453 & 0.0183 & 0.0465 & 0.0345 & 0.0914 \\
\hline
\end{tabular}

VILLAGE A

\begin{tabular}{|c|c|c|c|c|c|c|}
\hline & $(1)^{*}$ & $(2)^{*}$ & $(3)^{*}$ & $(4)^{*}$ & $(5)^{*}$ & $(6)^{*}$ \\
\hline Vulnerability & $-0.0913 \quad(0.498)$ & & & $-0.1023 \quad(0.457)$ & $0.2643(0.250)$ & $-0.0237 \quad(0.862)$ \\
\hline Avg. Cons. & & $-0.0006 \quad(0.085)$ & & $-0.0006 \quad(0.090)$ & & $-0.0006 \quad(0.112)$ \\
\hline Agric. Land & & & $-0.0000 \quad(0.348)$ & & & $-0.0001 \quad(0.141)$ \\
\hline Poor (Dummy) & & & & & $0.2148 \quad(0.042)$ & \\
\hline Vuln. x Poor & & & & & $-0.4863 \quad(0.081)$ & \\
\hline Female headed & & & & & & $-0.1479 \quad(0.355)$ \\
\hline Age of Head & & & & & & $-0.0035 \quad(0.515)$ \\
\hline Household Size & & & & & & $0.0623 \quad(0.231)$ \\
\hline HH Structure & & & & & & $0.3507 \quad(0.043)$ \\
\hline Uneduc. Head & & & & & & $0.0171 \quad(0.873)$ \\
\hline \# Old in $\mathrm{HH}$ & & & & & & $-0.1114 \quad(0.429)$ \\
\hline \# Children in $\mathrm{HH}$ & & & & & & $-0.0719 \quad(0.265)$ \\
\hline Pseudo $\mathrm{R}^{\wedge} 2$ & 0.0028 & 0.0209 & 0.0126 & 0.0241 & 0.0376 & 0.1383 \\
\hline
\end{tabular}

\begin{tabular}{|c|c|c|c|c|c|c|}
\hline \multirow{14}{*}{$\begin{array}{l}\text { Vulnerability } \\
\text { Avg. Cons. } \\
\text { Agric. Land } \\
\text { Poor (Dummy) } \\
\text { Vuln. x Poor } \\
\text { Female headed } \\
\text { Age of Head } \\
\text { Household Size } \\
\text { HH Structure } \\
\text { Uneduc. Head } \\
\text { \# Old in HH } \\
\text { \# Children in HH }\end{array}$} & \multicolumn{6}{|c|}{ VILLAGE B } \\
\hline & $(1)^{*}$ & $(2)^{*}$ & $(3)^{*}$ & $(4)^{*}$ & $(5)^{*}$ & $(6)^{*}$ \\
\hline & $0.1378 \quad(0.048)$ & & & 0.1006 & $-0.0263(0.908)$ & $0.0506 \quad(0.441)$ \\
\hline & & $-0.0007 \quad(0.003)$ & & $-0.0006 \quad(0.005)$ & & $-0.0006 \quad(0.029)$ \\
\hline & & & $-0.0001 \quad(0.219)$ & & & $0.0000 \quad(0.146)$ \\
\hline & & & & & $0.1715 \quad(0.068)$ & \\
\hline & & & & & $0.1672 \quad(0.481)$ & \\
\hline & & & & & & $0.2853 \quad(0.059)$ \\
\hline & & & & & & $-0.0130 \quad(0.003)$ \\
\hline & & & & & & $-0.0402 \quad(0.323)$ \\
\hline & & & & & & $-0.2812 \quad(0.005)$ \\
\hline & & & & & & $0.0692 \quad(0.463)$ \\
\hline & & & & & & $0.1114 \quad(0.278)$ \\
\hline & & & & & & $0.0234 \quad(0.659)$ \\
\hline Pseudo $R^{\wedge} 2$ & 0.0193 & 0.0653 & 0.0286 & 0.0763 & 0.0579 & 0.2517 \\
\hline
\end{tabular}

*The marginal effects $\mathrm{dF} / \mathrm{dx}$, evaluated at the sample mean, are reported here. P-values are reported in parentheses.

*All statistics are weighed to correctly reflect the proportion of female-headed households in the population. 
Figure 1a: CARA Utility

Vulnerability Coefficients with $90 \%$ Confidence Intervals, Village A

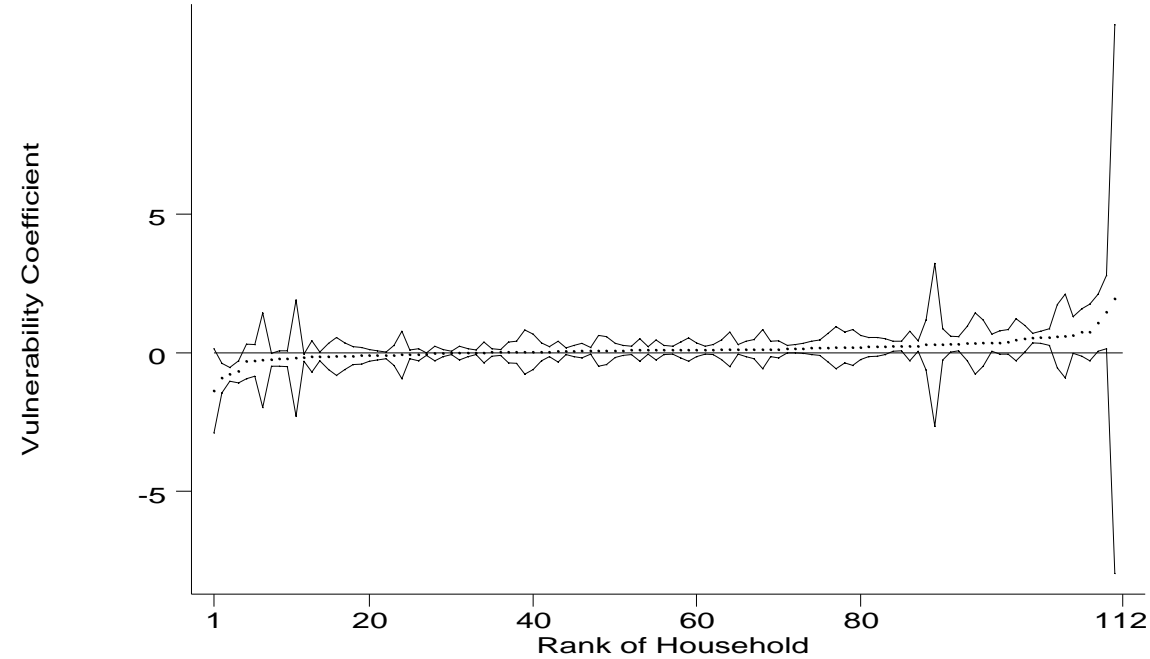

Figure 1c: CRRA Utility

Vulnerability Coefficients with $90 \%$ Confidence Intervals, Village A

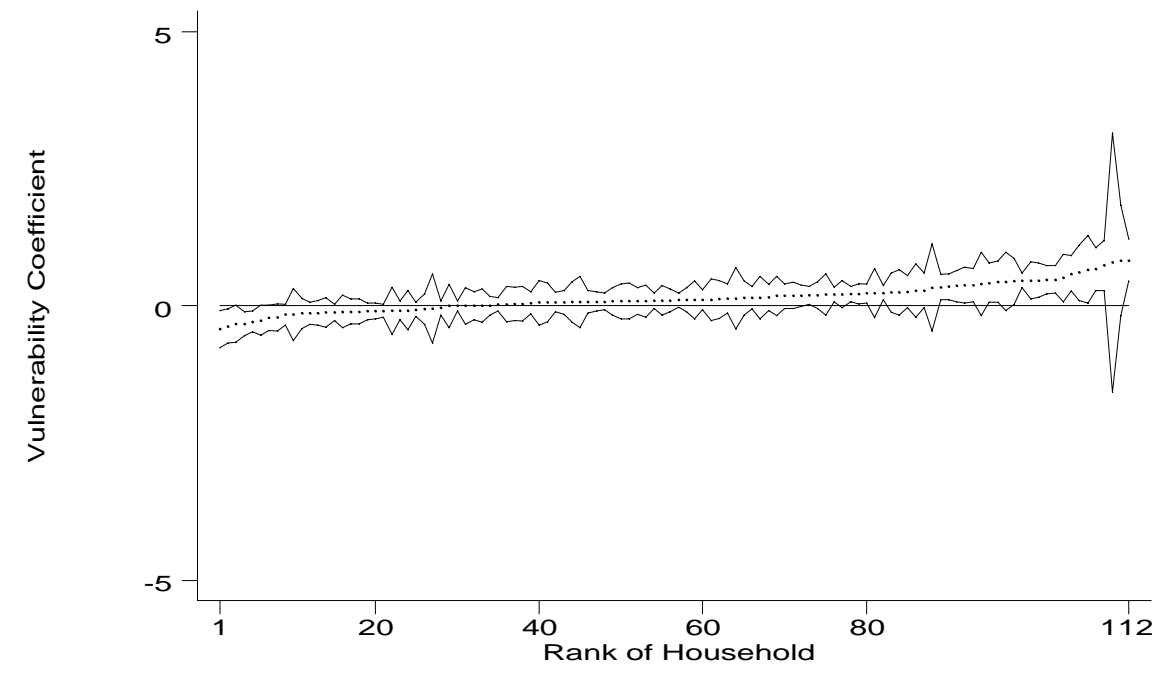

Figure 1b: CARA Utility

Vulnerability Coefficients with $90 \%$ Confidence Intervals, Village B

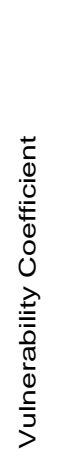

o

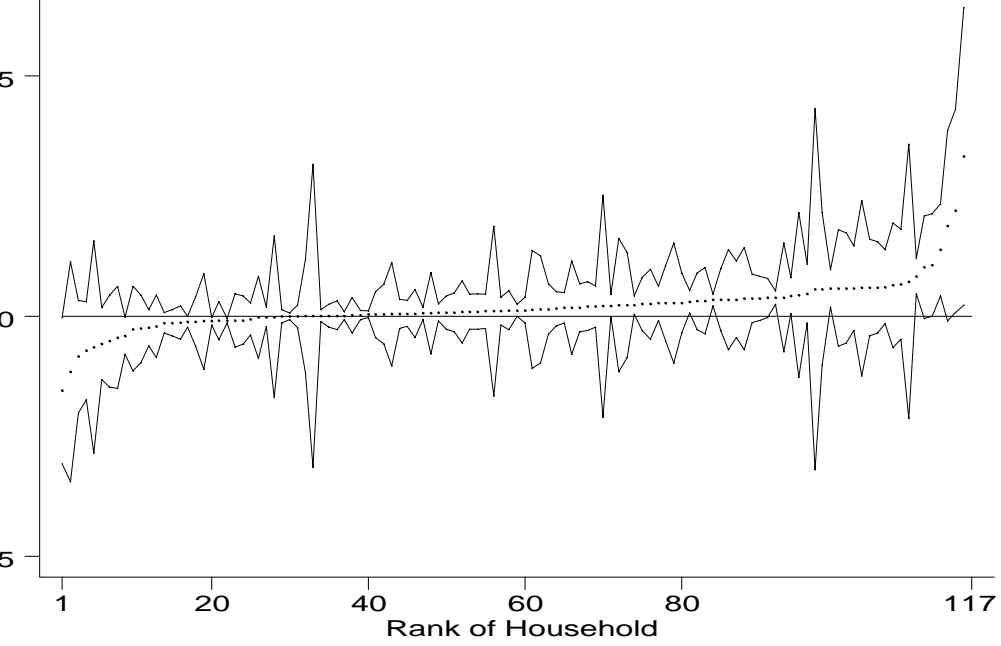

Vulnerability Coefficients with $90 \%$ Confidence Intervals, Village B

0
+
$\frac{1}{0}$
$\frac{0}{0}$
$\frac{2}{0}$
0
0
$\frac{1}{7}$
$\frac{0}{0}$
$\frac{\pi}{0}$
$\frac{5}{3}$
$>$ \begin{tabular}{|}
$5-$ \\
$0-$ \\
$-5-$
\end{tabular}

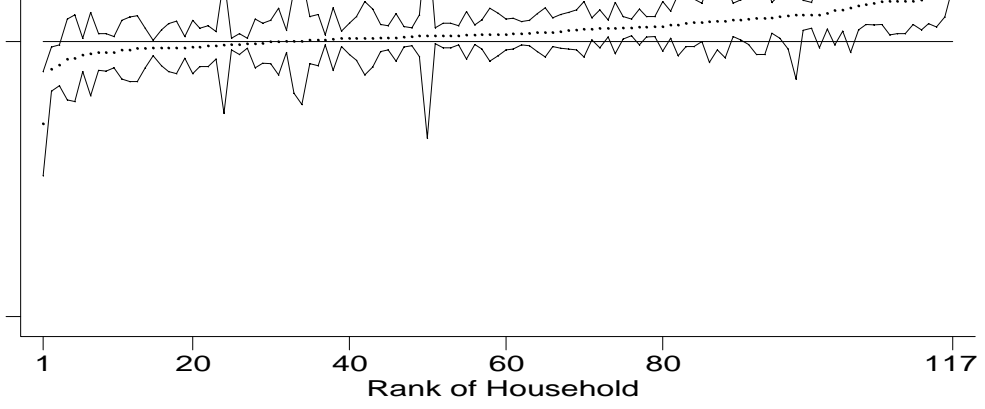



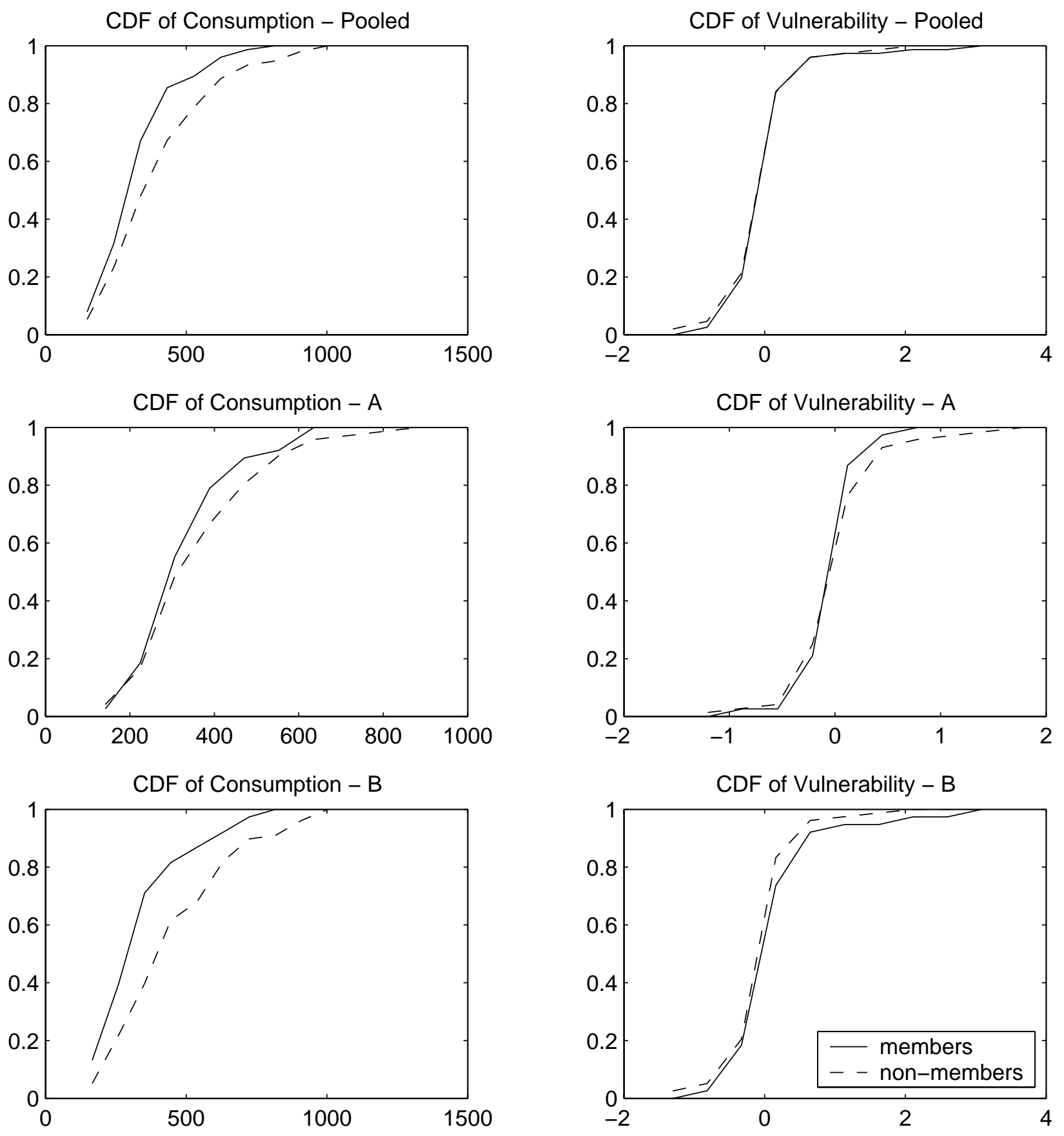

FIGURE 2: Poverty, Vulnerability and Microcredit Membership 